\title{
Antimalarial Activity of Aqueous and 80\% Methanol Crude Seed Extracts and Solvent Fractions of Schinus molle Linnaeus (Anacardiaceae) in Plasmodium berghei-Infected Mice
}

\author{
Getu Habte $\mathbb{D}^{1},{ }^{1,2}$ Teshome Nedi $\mathbb{D}^{1},{ }^{1}$ and Solomon Assefa ${ }^{1}{ }^{1}$ \\ ${ }^{1}$ Department of Pharmacology and Clinical Pharmacy, School of Pharmacy, College of Health Sciences, Addis Ababa University, \\ P.O. Box 1176, Addis Ababa, Ethiopia \\ ${ }^{2}$ Department of Pharmacy, College of Health Sciences, Mettu University, P.O. Box 318, Addis Ababa, Ethiopia
}

Correspondence should be addressed to Getu Habte; getu.habte@meu.edu.et

Received 14 July 2019; Accepted 14 January 2020; Published 18 February 2020

Academic Editor: Sukla Biswas

Copyright (c) 2020 Getu Habte et al. This is an open access article distributed under the Creative Commons Attribution License, which permits unrestricted use, distribution, and reproduction in any medium, provided the original work is properly cited.

Background. Malaria is among the leading causes of mortality and morbidity. Moreover, the emergence of resistance to antimalarial drugs is a major problem in controlling the disease. This makes the development of novel antimalarial drugs a necessity. Medicinal plants are important sources in discovering antimalarial drugs. Schinus molle is claimed for its antimalarial effect in Ethiopian folkloric medicine and endowed with in vitro antiplasmodial activity. In the present study, the in vivo antimalarial activity of the plant was investigated. Methods. Acute toxicity was carried out using a standard procedure. To screen the in vivo antimalarial potential of the $S$. molle against Plasmodium berghei (ANKA), a 4-day suppressive test was employed. The extracts and fractions were given to infected mice by oral gavage at 100,200 , and $400 \mathrm{mg} / \mathrm{kg} /$ day for four consecutive days. Parameters such as parasitemia were then evaluated. Results. Any sign of toxicity was not observed in the oral acute toxicity test. The crude extracts and solvent fractions exerted a significant $(p<0.05)$ inhibition of parasite load compared to the negative control. The highest inhibition (66.91\%) was exhibited by the $400 \mathrm{mg} / \mathrm{kg} /$ day dose of $80 \%$ methanolic crude extract. Among the fractions, chloroform fraction demonstrated maximal chemosuppressive effect (55.60\%). Moreover, crude extracts and solvent fractions prevented body weight loss, reduction in temperature, and anemia compared to the negative control. Except the aqueous fraction, the tested plant extracts were able to significantly prolong the survival time of infected mice. Conclusion. The findings of the present study confirmed the safety and a promising in vivo antimalarial activity of $S$. molle, thus supporting the traditional claim and in vitro efficacy. In-depth investigations on the plant, however, are highly recommended.

\section{Background}

Malaria is a protozoal disease caused by parasites of the genus Plasmodium and primarily transmitted to human and other animals by a female anopheline mosquito $[1,2]$. Besides, there are uncommon modes of malaria transmission such as congenital, blood transfusions, organ transplantation, and contaminated needles [3]. Five of the Plasmodium species, $P$. falciparum, $P$. vivax, $P$. ovale, $P$. malariae, and $P$. knowlesi, have been well known to cause human malaria $[4,5]$.

Globally, an estimated 3.2 billion people are at risk of being infected with malaria [6]. The burden is particularly the heaviest in the African region, where an estimated $90 \%$ of all malaria deaths occur [7]. Children aged less than 5 years account for $78 \%$ of all deaths [8]. Furthermore, pregnant women are highly vulnerable to malaria $[6,9]$. In many parts of sub-Saharan Africa, the malaria eradication program, which was launched in the 1950s and 1960s, had little success [10]. Ethiopia, like other sub-Saharan African countries, shares the intolerable burden of malaria, which has become a leading public health problem in the country [3].

In developing countries, malaria is still the leading cause of outpatient visits and hospital admission. Development and spread of antimalarial drug resistance has been the major challenge towards the control of the disease $[11,12]$. 
More importantly, there are alarming reports on parasite resistance to currently existing first-line drug regimen, ACTs [13]. This problem urges the search for new and improved antimalarial drugs $[12,14]$.

Medicinal plants played a crucial role as a source for antimalarial drugs including artemisinin and quinine $[15,16]$. The seed of the experimental plant, Schinus molle, is used as folk medicine for treatment of malaria in different parts of Ethiopia [17-19]. The plant, moreover, possesses an in vitro antimalarial activity [20]. Consequently, based on the traditional claim and reported in vitro antimalarial activity, the present study evaluated the in vivo antimalarial activity of crude seed extracts and solvent fractions of $S$. molle.

\section{Materials and Methods}

2.1. Experimental Animals. In this study, healthy Swiss albino mice (weighing 25-31 g and 6-8 weeks of age), bred and maintained in the animal house of School of Pharmacy, Addis Ababa University, were used. Animals were acclimatized for one week to the experimental environment before the actual experiment. They were housed in polypropylene cages and maintained at 12-hour light-dark cycle. Animals were provided with a commercial food and water ad libitum. All procedures and techniques used in this study were in accordance with internationally accepted guideline [21].

2.2. Collection of Experimental Plant. The ripened fruits of $S$. molle were collected from Sasiga District, western Ethiopia, where it has an established traditional claim for the treatment of malaria. Identification and authentication of the plant was done by a taxonomist at the National Herbarium, College of Natural and Computational Sciences, Addis Ababa University, where a voucher specimen was coded (GH 01/2017) and deposited for future reference.

2.3. Preparation of Crude Extracts. The collected ripened fruits of the plant were thoroughly washed with tap water and cleaned with gauze to remove debris. Then, the fruits were air-dried under shade, and the covering was removed by meshing. The resulting woody seeds were pulverized using mortar and pestle to get a coarse powder $(1050 \mathrm{~g})$. Then, the powder was separated into 2 parts: $300 \mathrm{~g}$ for aqueous extraction and the other $750 \mathrm{~g}$ of the powder for $80 \%$ methanol extraction. For both extractions, a mechanical shaker (Bibby Scientific Limited, Stone, Staffordshire, UK) was employed to facilitate the extraction process.

The aqueous extract was prepared as described by Yacob et al. [22]. Pulverized seeds (150 mg) were soaked in $1500 \mathrm{ml}$ of distilled water using an Erlenmeyer flask and the extraction process was facilitated with occasional stirring at $120 \mathrm{rpm}$ for 72 hours. The resulting distillate containing the aqueous crude extract was then separated from the marc with gauze and further filtered by Whatman filter paper number 1 (Whatman ${ }^{\circledR}$, England) under suction filtration. The same procedure was done for the other $150 \mathrm{mg}$ of pulverized seeds in $1500 \mathrm{ml}$ of distilled water. The extracts from both the procedures were then combined in a round bottom flask and deep-freezed at $-27^{\circ} \mathrm{C}$ and lyophilized (Operon, Korea Vacuum Limited, Korea) for one week to yield a solid residue.

Methanol extraction was done according to Bantie et al. [23] with slight modification. Accordingly, $150 \mathrm{mg}$ of coarse powder was soaked in $1500 \mathrm{ml}$ of $80 \%$ methanol in an Erlenmeyer flask. After 72 hours, the resulting distillate containing the $80 \%$ methanol crude extract was separated from the marc with gauze and further filtered by Whatman filter paper under suction filtration. The same procedure was done for the left $600 \mathrm{mg}$ of the coarse powder extracting $150 \mathrm{mg}$ at a time. Rotary evaporator (Buchi Rotavapor R-200, Switzerland) and a lyophilizer were used to remove methanol and concentrate the extract, respectively. Finally, a total of $84 \mathrm{~g}$ ( $11.20 \%$ yield) and $24 \mathrm{~g}$ ( $8.00 \%$ yield) of methanol and aqueous dry extracts were harvested, respectively, and the dried extracts were kept at $-20^{\circ} \mathrm{C}$ until use.

2.4. Fractionation of $80 \%$ Methanol Crude Extract. The extract with a better antimalarial effect (methanolic extract) was subjected to fractionation using solvents of differing polarity (chloroform, $n$-butanol, and water). Accordingly, 42 grams of the $80 \%$ methanol crude extract was suspended in $350 \mathrm{ml}$ of distilled water using a separatory funnel. Then, the suspension was successively shaken with $100 \mathrm{ml}$ of chloroform and $n$-butanol. All the dried fractions were transferred into an amber glass bottle and stored at $-20^{\circ} \mathrm{C}$, until use. The percentage yield of chloroform, butanol, and aqueous fractions was $45.52 \%, 35.21 \%$, and $18.27 \%$, respectively.

2.5. Acute Toxicity Test. Oral acute toxicity test was performed according to OECD no. 425 guideline [24]. First, 5 overnight fasted female mice, one for each crude extract and fraction, was weighed and dosed with $2000 \mathrm{mg} / \mathrm{kg}$ of test substance, given via oral gavage as a single dose. Food was then withheld for further 2 hours. Then, each mouse was observed over a period of 24 hours. Since no death was observed, the same dose was given for four female mice and they were observed for gross behavioral changes such as loss of appetite, hair erection, lacrimation, tremors, convulsions, and mortality for a period of 14 days.

\subsection{In Vivo Antimalarial Screening}

2.6.1. Grouping and Dosing of Animals. For screening the in vivo antimalarial activity of crude seed extracts and three solvent fractions of $S$. molle, infected male Swiss albino mice were used. Mice were randomly assigned to five groups of 6 mice per group, separately for each crude extract and fraction. The first three groups for each crude extract and fraction received $100 \mathrm{mg} / \mathrm{kg}$ (G-I), $200 \mathrm{mg} / \mathrm{kg}$ (G-II), and $400 \mathrm{mg} / \mathrm{kg}$ (G-III) doses of the treatment, daily for four consecutive days. Dose selection was made based on the result of acute toxicity and preliminary study conducted on 
the extracts. The remaining two groups for each crude extract and fraction served as negative control (G-IV) and were provided with solvents for reconstitution (Tween $802 \% \mathrm{v} / \mathrm{v}$ for the chloroform and butanol fraction and methanol extract or distilled water for the aqueous fraction and extract) $(\mathrm{CON})$, while positive control $(\mathrm{G}-\mathrm{V})$ received $10 \mathrm{mg} / \mathrm{kg}$ of chloroquine phosphate (CQ).

2.6.2. Four-Day Suppressive Test. Chloroquine-sensitive $P$. berghei ANKA strain was obtained from Ethiopian Public Health Institute (EPHI). The parasites were then maintained by serial passage of blood from infected mice to noninfected ones every week until $30-37 \%$ of parasitemia level was attained [25]. Mouse with the aforementioned level of rising parasitemia was used as a donor.

In vivo antimalarial activity of the crude extracts and solvent fractions against early chloroquine-sensitive $P$. berghei infection was then carried out according to the 4-day suppressive test described by Peter et al. [26]. First, the parasitemia level of the donor mice was determined from the blood collected by cutting a 0.5 to $1 \mathrm{~mm}$ section from tail of the mice with scissors. Donor mice were thus sacrificed and blood collected by cardiac puncture into a falcon tube containing $2 \%$ trisodium citrate as anticoagulant $[23,27]$. The collected blood samples from all donor mice were pooled together to avoid variability and then diluted in normal saline [23]. The dilution was made based on parasitemia of the donor mice and $\mathrm{RBC}$ count of the normal mice in such a way that $1 \mathrm{ml}$ blood contains $5 \times 10^{7}$ infected RBCs [28].

On the first day (D0), each apparently healthy mouse was infected intraperitoneally with $0.2 \mathrm{ml}$ of blood containing about $1 \times 10^{7}$ P. berghei-infected RBCs. Then, treatment was started $3 \mathrm{hrs}$ after inoculation and continued daily for three consecutive days (D1-D3). On the $5^{\text {th }}$ day (D4), parameters detailed below were determined and mice were monitored daily for 30 days to determine survival time [26].

\subsubsection{Determination of Parasitemia and Survival Time.} On D4, blood was collected from the tail of each mouse using clean and nongreasy slides to prepare thin films. After being allowed to air-dry, slides were viewed microscopically using the $\times 100$ objective. The percentage parasitemia (PP) was obtained by counting the number of parasitized RBCs (PRBCs) out of erythrocytes in random fields of the microscope. Two stained slides for each mouse were examined. Three fields with approximately 200-500 cells were counted for each slide and PP for each mouse was determined using the following formula [29-31]:

$$
\mathrm{PP}=\frac{\mathrm{PRBC}}{\text { total number of RBCs counted }} \times 100 .
$$

The mean percentage parasitemia suppression (PPS) was calculated using the formula described below [29, 30]:

$$
\text { PPS }=\frac{(\text { mean PP in negative control }- \text { mean PP in treatment group) }}{\text { mean PP in negative control }} \times 100 .
$$

The mean survival time (MST) for each group was calculated as follows [28]:

$$
\text { MST }=\frac{\text { sum of survival time of all mice in a group (days) }}{\text { total number of mice in that group }} .
$$

2.6.4. Determination of Weight, Temperature, and Packed Cell Volume. Weight and rectal temperature of each mouse were recorded just before treatment and after treatment on D4. The mean percentage changes were then calculated and analyzed for each group [26]. In the same way, packed cell volume (PCV) was measured before and after treatment. To determine PCV, blood was collected from the tail of each mouse in heparinized microhematocrit capillary tubes. The capillary tubes were filled to $3 / 4^{\text {th }}$ of their height with blood and sealed with sealing clay at their dry end. The tubes were then placed on a microhematocrit centrifuge (Centurion Scientific, UK) with the sealed end facing the periphery and centrifuged at $11,000 \mathrm{rpm}$ for 5 minutes [23]. Finally, the tubes were taken out of the centrifuge and PCV was determined using the standard hematocrit reader (Hawksley and Sons, England) according to the formula indicated below [31, 32]:

$$
\mathrm{PCV}=\frac{\text { volume of erythrocyte in a given volume of blood }}{\text { total blood volume examined }} \times 100 \text {. }
$$

2.7. Phytochemical Screening. Crude seed extracts and solvent fractions of $S$. molle were screened for the presence of major phytochemical constituents. Accordingly, tests for alkaloids, saponins, tannins, flavonoids, phenols, cardiac glycosides, steroids, and terpenoids were performed following standard procedures as described below $[33,34]$.

2.8. Data Analysis. The collected data were organized, entered, and analyzed using SPSS version 22. One-way analysis of variance (ANOVA) followed by Tukey's posthoc test was used to compare the mean PPS, MST, changes in mean body weight, PCV, and rectal temperature of the $P$. berghei-infected mice between the test groups and the respective control and among different test groups in each test. The analysis at $95 \%$ confidence interval and $p$ value less than 0.05 was considered to be statistically significant. 


\section{Results}

3.1. Acute Toxicity Test. Acute toxicity test revealed that no mortality was observed within the first $24 \mathrm{~h}$ and the next 14 days of the observation period. The gross behavioral and physical observation of the experimental mice, furthermore, indicated that the plant caused no visible signs of acute toxicity.

\subsection{4-Day Suppressive Test}

\subsubsection{Effect on Parasitemia and Survival Time}

(1) Crude Extract. The chemosuppressive effect of the plant is summarized in Table 1. All dose levels of each crude seed extract evaluated in the study exhibited a statistically significant $(p<0.05)$ difference in reducing parasite load compared to negative control. The highest percentage of parasitemia inhibition $(66.91 \%)$ was exhibited by $80 \%$ methanol extract at $400 \mathrm{mg} / \mathrm{kg} /$ day dose. Nevertheless, the effect produced by the crude extracts was inferior to the standard drug, which cleared the parasite to undetectable level. The $80 \%$ methanol crude seed extract of $S$. molle exhibited the longest mean survival time (13.83 days) at the highest dose given.

(2) Fractions. The solvent-fraction-treated group revealed a significant $(p<0.05)$ reduction of parasite load compared to negative controls at all doses in a dose-dependent fashion. The highest inhibition (55.60\%), however, was exhibited by the chloroform fraction. Chloroform and butanol fractions were able to significantly $(p<0.05)$ prolong the survival time in a dose-dependent manner (Table 1). In all experiments, CQ-treated groups survived throughout the monitoring period ( $>30$ days).

\subsubsection{Effect on Body Weight and Rectal Temperature}

(1) Crude Extracts. The three doses of methanol fraction and highest dose of aqueous fraction $(600 \mathrm{mg} / \mathrm{kg})$ significantly $(p<0.05)$ averted body weight loss compared to the negative control. Moreover, all dose levels of the hydromethanolic extract and two dose levels of aqueous extracts $(200 \mathrm{mg} / \mathrm{kg}$ and $400 \mathrm{mg} / \mathrm{kg}$ ) were able to significantly prevent body temperature dropping due to parasite infection compared to those in the vehicle-treated groups (Table 2).

(2) Fractions. Compared to the negative control, all dose levels of chloroform fractions and butanol fraction as well as highest dose of aqueous fraction exhibited a significant $(p<0.05)$ and dose-dependent protection against body weight loss and rectal temperature dropping. The highest protection in both weight and temperature reduction was exhibited by the chloroform fraction at the highest dose given, $400 \mathrm{mg} / \mathrm{kg} /$ day (Table 2).

\subsubsection{Effect on Packed Cell Volume}

(1) Crude Extracts. Significant protection against reduction of PCV $(p<0.05)$ was exhibited in both the aqueous and $80 \%$
TABLE 1: The effect of crude seed extracts and solvent fractions of $S$. molle on parasitemia and survival time of $P$. berghei-infected mice.

\begin{tabular}{|c|c|c|c|}
\hline Group & $\%$ parasitemia & $\%$ suppression & Survival time (day) \\
\hline 80ME100 & $33.01 \pm 0.92$ & $35.72^{\mathrm{a}^{*}, \mathrm{c}^{*}, \mathrm{~d}^{*}, \mathrm{e}^{*}}$ & $9.50 \pm 0.43^{\mathrm{a}^{*}, \mathrm{~d}^{*}, \mathrm{e}^{*}}$ \\
\hline $80 \mathrm{ME} 200$ & $22.75 \pm 0.83$ & $55.70^{\mathrm{a}^{*}, \mathrm{~b}^{*}, \mathrm{~d}^{*}, \mathrm{e}^{*}}$ & $10.17 \pm 0.48^{\mathrm{a} *, \mathrm{~d}^{*}, \mathrm{e}^{*}}$ \\
\hline 80ME400 & $16.99 \pm$ & $66.91^{\mathrm{a}^{*}, \mathrm{~b}^{*}, \mathrm{c}^{*}, \mathrm{e}^{*}}$ & $13.83 \pm 0.87^{\mathrm{a}^{*}, \mathrm{~b}^{*}, \mathrm{c}^{*}, \mathrm{e}^{*}}$ \\
\hline $\mathrm{CON}$ & $51.35 \pm 1.66$ & 0.00 & $6.33 \pm 0.49$ \\
\hline CQ10 & $0.00 \pm 0.00$ & $100.00^{\mathrm{a}^{*}}$ & $>30.00 \pm 0.00^{\mathrm{a}^{*}}$ \\
\hline AE100 & $38.00 \pm 1.32$ & $27.18^{\mathrm{a}^{*}, \mathrm{c}^{*}, \mathrm{~d}^{*}, \mathrm{e}^{*}}$ & $6.50 \pm 0.34^{\mathrm{d}^{*}, \mathrm{e}^{*}}$ \\
\hline AE200 & $35.42 \pm$ & $32.15^{\mathrm{a}^{*}, \mathrm{~b}^{\mathrm{b}}, \mathrm{d}^{*}, \mathrm{e}^{*}}$ & $6.67 \pm 0.33^{\mathrm{d}^{*}, \mathrm{e}^{*}}$ \\
\hline AE400 & $33.89 \pm 1.32$ & $35.08^{\mathrm{a}^{*}, \mathrm{~b}^{*}, \mathrm{c}^{*}, \mathrm{e}^{*}}$ & $8.00 \pm 0.37^{\mathrm{a}^{*}, \mathrm{~b}^{*}, \mathrm{c}^{*}, \mathrm{e}^{*}}$ \\
\hline $\mathrm{CON}$ & $52.20 \pm 2.20$ & 0.00 & $6.33 \pm 0.21$ \\
\hline CQ10 & $0.00 \pm 0.00$ & $100.00^{\mathrm{a}^{*}}$ & $>30.00 \pm 0.00^{\mathrm{a}^{*}}$ \\
\hline CF100 & $37.52 \pm 1.10$ & $32.69^{\mathrm{a}^{*}, \mathrm{c}^{*}, \mathrm{~d}^{*}, \mathrm{e}^{*}}$ & $8.33 \pm 0.33^{\mathrm{a}^{*}, \mathrm{~d}^{*}, \mathrm{e}^{*}}$ \\
\hline CF200 & $34.02 \pm 0.93$ & $38.97^{\mathrm{a}^{*}, \mathrm{~b}^{*}, \mathrm{~d}^{*}, \mathrm{e}^{*}}$ & $9.17 \pm 0.31^{\mathrm{a}^{*}, \mathrm{~d}^{*}, \mathrm{e}^{*}}$ \\
\hline CF400 & $24.75 \pm 1.37$ & $55.60^{\mathrm{a}^{*}, \mathrm{~b}^{*}, \mathrm{c}^{*}, \mathrm{e}^{*}}$ & $12.17 \pm 0.48^{\mathrm{a}^{*}, \mathrm{~b}^{*}, \mathrm{c}^{*}, \mathrm{e}^{*}}$ \\
\hline $\mathrm{CON}$ & $55.74 \pm 1.06$ & 0.00 & $6.33 \pm 0.42$ \\
\hline CQ10 & $0.00 \pm 0.00$ & $100.00^{\mathrm{a}^{*}}$ & $>30.00 \pm 0.00^{\mathrm{a}^{*}}$ \\
\hline BF100 & $36.23 \pm 1.32$ & $31.49^{a^{*}, c^{*}, d^{*}, e^{*}}$ & $8.17 \pm 0.40^{\mathrm{a}^{*}, \mathrm{~d}^{*}, \mathrm{e}^{*}}$ \\
\hline BF200 & & $37.59^{\mathrm{a}^{*}, \mathrm{~b}^{*}, \mathrm{~d}^{*}, \mathrm{e}^{*}}$ & $8.67 \pm 0.49^{9^{*}, \mathrm{~d}^{*}, \mathrm{e}^{*}}$ \\
\hline BF400 & $29.28 \pm 1.67$ & $44.63^{\mathrm{a}^{*}, \mathrm{~b}^{*}, \mathrm{c}^{*}, \mathrm{e}^{*}}$ & $10.67 \pm 0.67^{\mathrm{a}^{*}, \mathrm{~b}^{*}, \mathrm{c}^{*}, \mathrm{e}^{*}}$ \\
\hline $\mathrm{CON}$ & $52.88 \pm 2.20$ & 0.00 & $6.17 \pm 0.31$ \\
\hline CQ10 & $0.00 \pm 0.00$ & $100.00^{\mathrm{a}^{*}}$ & $>30.00 \pm 0.00^{\mathrm{a}^{*}}$ \\
\hline AF100 & $43.52 \pm 0.92$ & $15.64^{\mathrm{a}^{*}, \mathrm{c}^{*}, \mathrm{~d}^{*}, \mathrm{e}^{*}}$ & $6.50 \pm 0.43^{\mathrm{e}^{*}}$ \\
\hline AF200 & $41.51 \pm 1.33$ & $19.54^{\mathrm{a}^{*}, \mathrm{~b}^{*}, \mathrm{~d}^{*}, \mathrm{e}^{*}}$ & $6.83 \pm 0.48^{\mathrm{e}^{*}}$ \\
\hline $\mathrm{AF} 400$ & $38.05 \pm 1.59$ & $26.25^{a^{*}, b^{*}, c^{*}, e^{*}}$ & $7.33 \pm 0.49^{\mathrm{e}^{*}}$ \\
\hline $\mathrm{CON}$ & $51.59 \pm 1.64$ & 0.00 & $6.33 \pm 0.33$ \\
\hline CQ10 & $0.00 \pm 0.00$ & $100.00^{\mathrm{a}^{*}}$ & $>30.00 \pm 0.00^{\mathrm{a}^{*}}$ \\
\hline
\end{tabular}

Data are expressed as mean $\pm \operatorname{SEM}(n=6)$; ${ }^{a}$ compared to either CON; b compared to $100 \mathrm{mg} / \mathrm{kg}$; ${ }^{\mathrm{c}}$ compared to $200 \mathrm{mg} / \mathrm{kg}$; ${ }^{\mathrm{d}}$ compared to $400 \mathrm{mg} /$ $\mathrm{kg}$; ${ }^{\mathrm{e}}$ compared to $\mathrm{CQ} 10$; and ${ }^{*} p<0.05 . \mathrm{AE}=$ aqueous crude extract, $80 \mathrm{ME}=80 \%$ methanol crude extract, $\mathrm{CF}=$ chloroform fraction, $\mathrm{BF}=\mathrm{bu}-$ tanol fraction, $\mathrm{AF}=$ aqueous fraction, $\mathrm{CON}=$ control, and $\mathrm{CQ}=$ chlor oquine base. Numbers after letters in the first column refer to dose in $\mathrm{mg} / \mathrm{kg}$.

methanol crude extracts compared to their respective negative controls. The highest protection against reduction of PCV was exhibited by $80 \%$ methanol crude seed extract at $400 \mathrm{mg} / \mathrm{kg} /$ day (Figure 1), while the lowest protection was exhibited by aqueous crude seed extract at $100 \mathrm{mg} / \mathrm{kg} /$ day (Figure 2).

(2) Fractions. Fractions protected infection-induced reduction in PCV. The highest protection was exhibited by the chloroform fraction of the $80 \%$ methanol crude seed extract at the highest dose given, $400 \mathrm{mg} / \mathrm{kg} /$ day (Figure 3), while the least protection among the three fractions was exhibited by the aqueous fraction at the least dose given, $100 \mathrm{mg} / \mathrm{kg} /$ day (Figures 3(a)-3(c)). The rank order of protection from infection-induced reduction in PCV was $80 \%$ methanol crude extract $>$ chloroform fraction $>$ butanol fraction $>$ aqueous extract $>$ aqueous fraction.

3.3. Phytochemical Screening. Phytochemical screening tests revealed that $80 \%$ methanol crude seed extract was positive for alkaloids, saponins, tannins, flavonoids, phenols, cardiac glycosides, steroids, and terpenoids. The least types of secondary metabolites were found in aqueous fraction, which was positive only for alkaloids, tannins, and phenols (Table 3). 
TABLE 2: Body weight and rectal temperature changes of $P$. berghei-infected mice treated with the crude seed extracts and solvent fractions of S. molle.

\begin{tabular}{|c|c|c|c|c|c|c|}
\hline \multirow{2}{*}{ Group } & \multicolumn{3}{|c|}{ Weight (g) } & \multicolumn{3}{|c|}{ Temperature $\left({ }^{\circ} \mathrm{C}\right)$} \\
\hline & D0 & D4 & Change & D0 & D4 & Change \\
\hline 80ME100 & $28.50 \pm 0.63$ & $26.47 \pm 0.68$ & 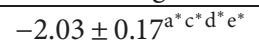 & $36.70 \pm 0.35$ & $35.50 \pm 0.36$ & 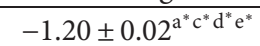 \\
\hline $80 \mathrm{ME} 200$ & $28.66 \pm 0.66$ & $27.53 \pm 0.69$ & $-1.13 \pm 0.13^{\mathrm{a}^{*} \mathrm{~b}^{*} \mathrm{~d}^{*} \mathrm{e}^{*}}$ & $37.05 \pm 0.32$ & $36.52 \pm 0.32$ & 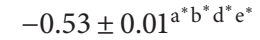 \\
\hline $80 \mathrm{ME} 400$ & $28.63 \pm 0.66$ & $28.42 \pm 0.66$ & 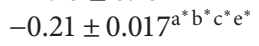 & $36.94 \pm 0.27$ & $36.70 \pm 0.27$ & 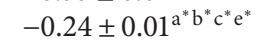 \\
\hline $\mathrm{CON}$ & $28.17 \pm 0.82$ & $24.54 \pm 0.50$ & $-3.63 \pm 1.46$ & $36.85 \pm 0.22$ & $34.47 \pm 0.27$ & $-2.38 \pm 0.06$ \\
\hline CQ10 & $28.52 \pm 0.79$ & $28.80 \pm 0.83$ & $0.28 \pm \pm^{\mathrm{a}^{*}}$ & $37.20 \pm 0.22$ & $38.00 \pm 0.21$ & $0.80 \pm 0.03^{\mathrm{a}^{*}}$ \\
\hline AE100 & $28.14 \pm 0.77$ & $24.68 \pm 0.77$ & $-3.46 \pm 0.64^{\mathrm{d}^{*} \mathrm{e}^{*}}$ & $37.15 \pm 0.44$ & $34.78 \pm 0.43$ & $-2.37 \pm 0.01^{\mathrm{c} * \mathrm{~d} * \mathrm{e} *}$ \\
\hline AE200 & $28.35 \pm 0.55$ & $24.89 \pm 0.55$ & $-3.45 \pm 0.01^{\mathrm{d}^{*} \mathrm{e}^{*}}$ & $36.88 \pm 0.22$ & $34.54 \pm 0.24$ & $-2.34 \pm 0.00^{\mathrm{a} * \mathrm{~b} * \mathrm{~d} * \mathrm{e} *}$ \\
\hline AE400 & $28.54 \pm 0.86$ & $25.38 \pm 0.84$ & 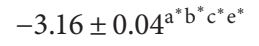 & $36.97 \pm 0.30$ & $35.12 \pm 0.29$ & 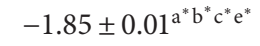 \\
\hline CON & $28.22 \pm 0.85$ & $24.74 \pm 0.88$ & $-3.48 \pm 0.10$ & $37.05 \pm 0.42$ & $34.69 \pm 0.41$ & $-2.36 \pm 0.04$ \\
\hline CQ10 & $28.23 \pm 0.50$ & $28.45 \pm 0.46$ & $0.22 \pm 0.057^{\mathrm{a}^{*}}$ & $36.99 \pm 0.28$ & $37.67 \pm 0.27$ & $0.68 \pm 0.04^{\mathrm{a}^{*}}$ \\
\hline CF100 & $28.44 \pm 0.80$ & $26.15 \pm 0.79$ & 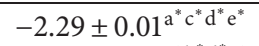 & $36.95 \pm 0.16$ & $35.29 \pm 0.15$ & 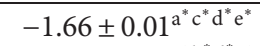 \\
\hline CF200 & $28.05 \pm 0.68$ & $26.63 \pm 0.69$ & $-1.42 \pm 0.02^{\mathrm{a}^{*} \mathrm{~b}^{*} \mathrm{~d}^{*} \mathrm{e}^{*}}$ & $36.99 \pm 0.29$ & $36.15 \pm 0.30$ & 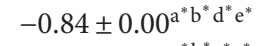 \\
\hline CF400 & $28.18 \pm 0.64$ & $27.64 \pm 0.63$ & $-0.54 \pm 0.01^{\mathrm{a}^{*} \mathrm{~b}^{*} c^{*} \mathrm{e}^{*}}$ & $36.89 \pm 0.29$ & $36.39 \pm 0.27$ & 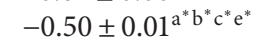 \\
\hline $\mathrm{CON}$ & $28.41 \pm 0.86$ & $24.82 \pm 0.57$ & $-3.59 \pm 0.85$ & $36.81 \pm 0.35$ & $34.48 \pm 0.32$ & $-2.33 \pm 0.06$ \\
\hline CQ10 & $28.59 \pm 0.88$ & $28.83 \pm 0.86$ & $0.24 \pm 0.04^{\mathrm{a}^{*}}$ & $37.02 \pm 0.32$ & $37.71 \pm 0.29$ & $0.70 \pm 0.05^{\mathrm{a}^{*}}$ \\
\hline BF100 & $28.28 \pm 0.39$ & $24.90 \pm 0.66$ & 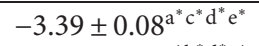 & $37.02 \pm 0.67$ & $35.04 \pm 0.66$ & 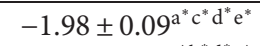 \\
\hline BF200 & $29.12 \pm 0.66$ & $26.47 \pm 0.67$ & 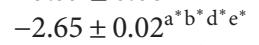 & $36.87 \pm 0.66$ & $35.74 \pm 0.67$ & 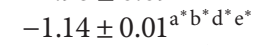 \\
\hline BF400 & $28.08 \pm 0.69$ & $26.65 \pm 0.70$ & $-1.43 \pm 0.01^{\mathrm{a}^{*} \mathrm{~b}^{*} \mathrm{c}^{*} \mathrm{e}^{*}}$ & $37.01 \pm 0.69$ & $36.26 \pm 0.70$ & 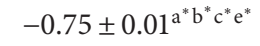 \\
\hline $\mathrm{CON}$ & $27.93 \pm 0.81$ & $24.28 \pm 0.79$ & $-3.65 \pm 0.09$ & $36.97 \pm 0.81$ & $34.66 \pm 0.80$ & $-2.31 \pm 0.08$ \\
\hline CQ10 & $28.24 \pm 0.61$ & $28.43 \pm 0.60$ & $0.19 \pm .03^{\mathrm{a}^{*}}$ & $36.92 \pm 0.62$ & $37.54 \pm 0.60$ & $0.62 \pm 0.05^{\mathrm{a}^{*}}$ \\
\hline AF100 & $28.33 \pm 0.68$ & $24.72 \pm 0.67$ & $-3.62^{\mathrm{d}^{*} \mathrm{e}^{*}}$ & $36.98 \pm 0.26$ & $34.66 \pm 0.26$ & $-2.32 \pm 0.01^{\mathrm{d}^{*} \mathrm{e}^{*}}$ \\
\hline $\mathrm{AF} 200$ & $28.34 \pm 0.57$ & $24.75 \pm 0.56$ & $-3.59^{\mathrm{d}^{*} \mathrm{e}^{*}}$ & $36.96 \pm 0.26$ & $34.61 \pm 0.27$ & $-2.35 \pm 0.02^{\mathrm{d}^{*} \mathrm{e}^{*}}$ \\
\hline AF400 & $28.05 \pm 0.79$ & $24.82 \pm 0.77$ & 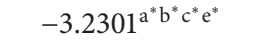 & $37.04 \pm 0.25$ & $34.79 \pm 0.24$ & 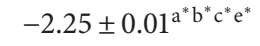 \\
\hline $\mathrm{CON}$ & $28.51 \pm 0.75$ & $24.86 \pm 0.81$ & -3.65 & $37.05 \pm 0.27$ & $34.72 \pm 0.34$ & $-2.33 \pm 0.10$ \\
\hline CQ10 & $28.45 \pm 0.67$ & $28.68 \pm 0.68$ & $0.22^{\mathrm{a}^{*}}$ & $36.89 \pm 0.22$ & $37.56 \pm 0.21$ & $0.67 \pm 0.06^{\mathrm{a}^{*}}$ \\
\hline
\end{tabular}

Data are expressed as mean $\pm \operatorname{SEM}(n=6)$; ${ }^{\mathrm{a}}$ compared to CON; ${ }^{\mathrm{b}}$ compared to $100 \mathrm{mg} / \mathrm{kg} ;{ }^{\mathrm{c}}$ compared to $200 \mathrm{mg} / \mathrm{kg} ;{ }^{\mathrm{d}}$ compared to $400 \mathrm{mg} / \mathrm{kg}$; ${ }^{\mathrm{e}}$ compared to CQ10; and ${ }^{*} p<0.05 . \mathrm{D} 0=$ pretreatment value on day $0, \mathrm{D} 4=$ posttreatment value on day four. $\mathrm{AE}=$ aqueous crude extract, $80 \mathrm{ME}=80 \% \mathrm{methanol} \mathrm{crude}$ extract, $\mathrm{CF}=$ chloroform fraction, $\mathrm{BF}=$ butanol fraction, $\mathrm{AF}=$ aqueous fraction, $\mathrm{CON}=$ control, and $\mathrm{CQ}=$ chloroquine base. Numbers after letters in the first column refer to dose in $\mathrm{mg} / \mathrm{kg}$.

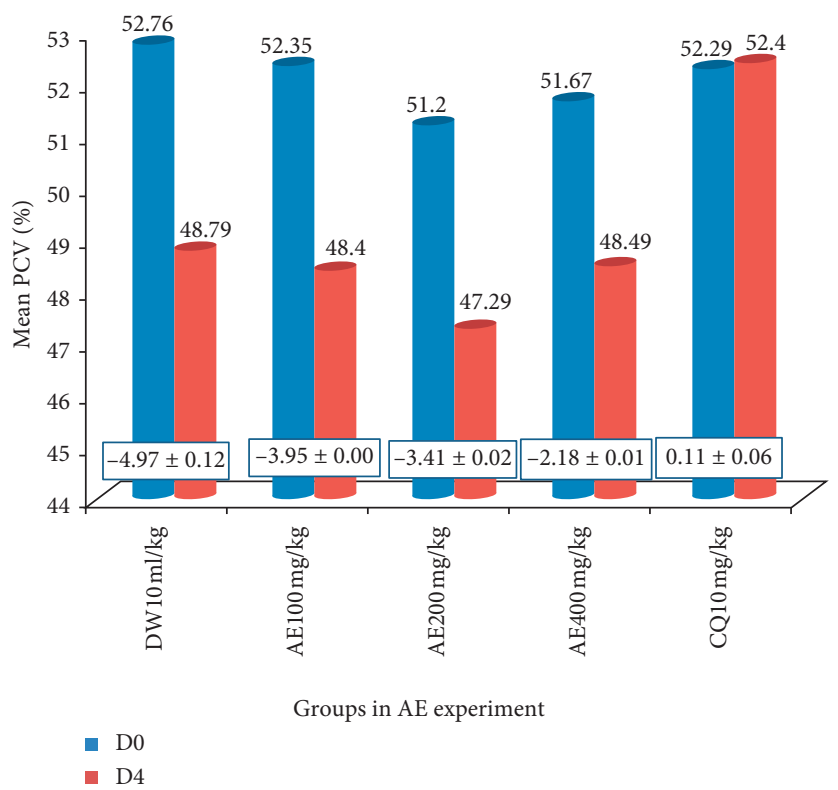

Figure 1: The effect of aqueous crude seed extract of $S$. molle on packed cell volume of $P$. berghei-infected mice. 


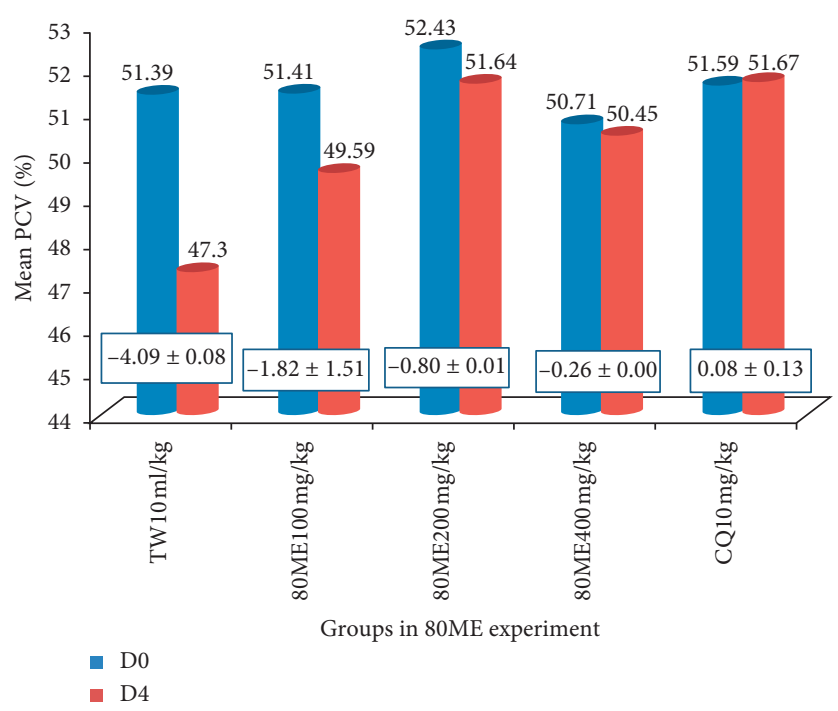

Figure 2: Effect of $80 \%$ methanol crude seed extract of $S$. molle on packed cell volume of $P$. berghei-infected mice. Data are expressed as mean $\pm \operatorname{SEM}(n=6)$; the difference in mean change in PCV was significant at $p<0.05$; DW: distilled water; TW: $2 \%$ Tween 80 ; CQ: chloroquine base; 80ME: 80\% methanol extract; AE: aqueous extract; PCV: packed cell volume; D0: pretreatment value on day 0; and D4: posttreatment value on day four. The numbers in rectangles between the graphs show the change in mean PCV between D0 and D4.

\section{Discussion}

Acute toxicity test suggested that the oral medial lethal dose (LD50) of the extracts and fractions could be greater than $2000 \mathrm{mg} / \mathrm{kg}$ [24]. This could justify the safe folkloric use of the seed of $S$. molle for the treatment of malaria by the local people in Ethiopia. Previous study [21], furthermore, reported the in vitro antimalarial effect of the plant. However, in vivo studies take into account prodrug effect and the role of immune system in controlling malaria infection unlike in vitro ones [30]. Therefore, to confirm the claimed antimalarial activities of the plant, a 4-day suppressive in vivo test was employed in the present study.

The finding of the study evidenced the significant inhibition of parasitemia by both the aqueous and $80 \%$ methanol crude seed extracts and all the three fractions of the seed of S. molle. The $80 \%$ methanol crude extract and aqueous fraction exhibited the maximum and minimum chemosuppression effect, respectively. This is in agreement with a similar study done on Croton macrostachyus by Bantie et al. [23]. On the contrary, a study conducted by Fantahun et al. [35] on Strychnos mitis reported the highest antimalarial effect of its aqueous crude extract.

Among the solvent fractions evaluated, the highest parasite inhibition was exhibited by the chloroform fraction. This finding is consistent with other studies [28, 36], in which the chloroform fractions showed higher chemosuppressive activity than the aqueous fraction. This suggests that the active bioactive agents are concentrated in nonpolar fraction.

The bioactive secondary metabolites revealed in phytochemical analysis could be responsible for the antimalarial activity of the plant [23]. The terpenoids, phenolic compounds, and flavonoids observed in this plant have been proved to possess potential immunomodulatory, anti-inflammatory, and antioxidant activity $[37,38]$. Therefore, the chemosuppressive effect could be via indirect boosting of the immune system or inhibition of other target pathways which are not fully realized [32].

An ideal antimalarial agents derived from plants are expected to prevent reduction in PCV, body weight loss, and reduction in body temperature due to the development of parasitemia [29]. Even though a significant prevention of body weight loss was exhibited by crude extracts and the solvent fractions compared to negative control, the mean value of the body weight showed reduction in treatment groups. Similarly, PCV was measured to evaluate the effectiveness of the plant in ablating malariainduced hemolysis. Chloroform fraction exhibited the maximal protection of hemolysis compared to the two other fractions. The mean value of the PCV and body weight, however, showed reduction in mice treated with the crude extracts and fractions on day 4 as compared to day 0 . These could be attributed to the inability of the extracts and fractions to completely clear the parasites from the bodies of the mice other than reduction to different levels [28, 32].

The three doses of methanolic extract and the middle and higher doses of aqueous extract of tested plant and all doses of the chloroform and butanol fractions significantly prevented rectal temperature dropping due to parasitemia. These activities probably indicate that the extracts ameliorate some pathological processes that cause reduction in internal body temperature and metabolic rates [23, 31].

If antimalarial activity of a compound displayed a percent growth inhibition of $>50 \%$ at a dose of 500-250, 250-100, and 


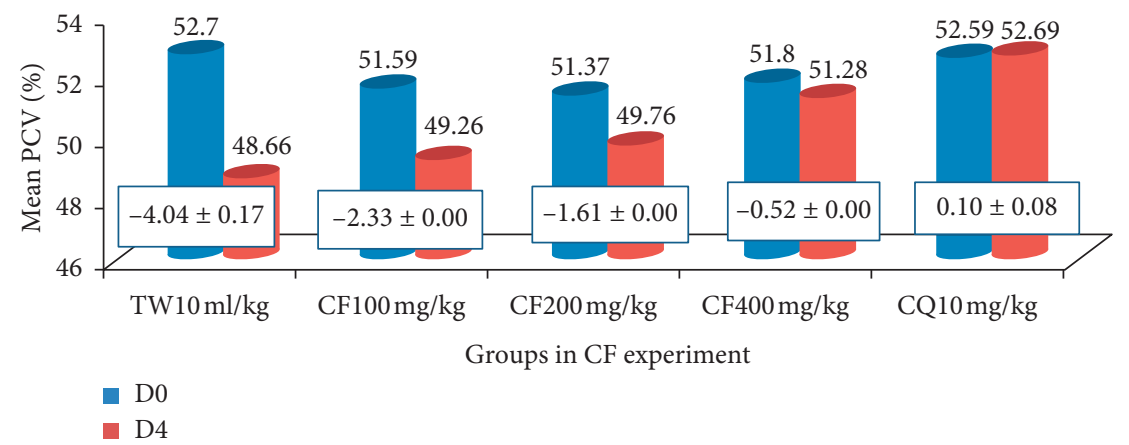

(a)

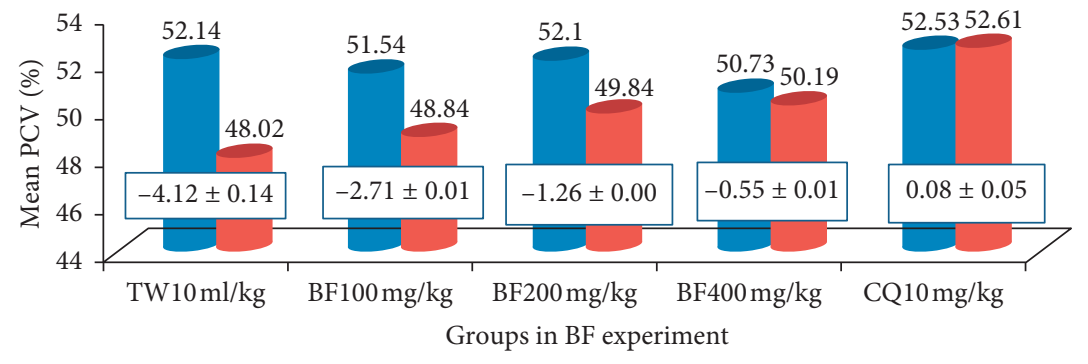

(b)

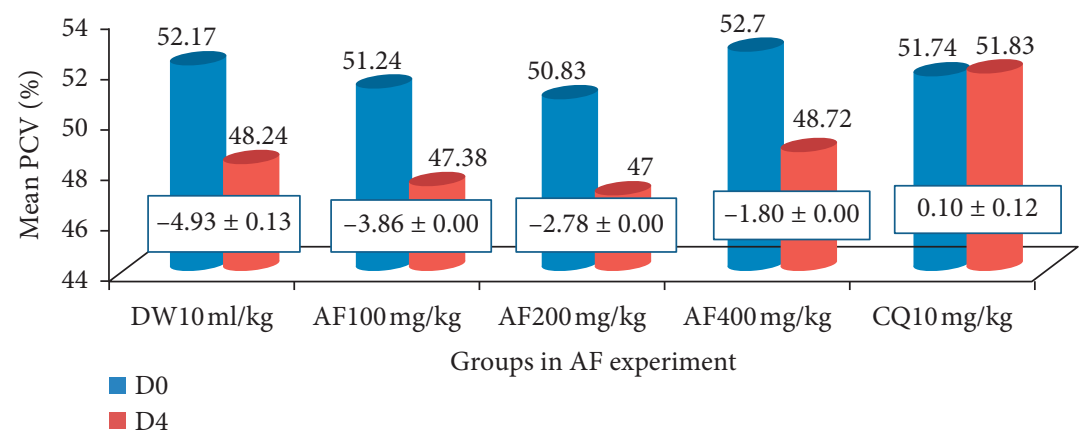

(c)

FIGURE 3: The effect of solvent fraction of $S$. molle $(\mathrm{A}=\mathrm{CF}, \mathrm{B}=\mathrm{BF}$, and $\mathrm{C}=\mathrm{AF})$ on packed cell volume of $P$. berghei-infected mice. Data are expressed as mean \pm SEM $(n=6)$; TW: negative control, $2 \%$ Tween 80 ; DW: distilled water CQ, positive control, chloroquine base; CF: chloroform fraction; BF: butanol fraction; AF: aqueous fraction; PCV: packed cell volume; D0: pretreatment value on day 0; and D4: posttreatment value on day four. The numbers in rectangles between graphs show the change in mean PCV between D0 and D4.

TABLE 3: Phytoconstituents of crude extracts and solvent fractions of the seed of S. molle.

\begin{tabular}{|c|c|c|c|c|c|}
\hline Phytochemicals & $80 \%$ methanol crude extract & Aqueous crude extract & Chloroform fraction & Butanol fraction & Aqueous fraction \\
\hline Alkaloids & + & + & + & + & + \\
\hline Tannins & + & + & + & + & + \\
\hline Saponins & + & + & + & + & - \\
\hline Flavonoids & + & + & + & + & - \\
\hline Terpenoids & + & - & + & - & - \\
\hline Steroids & + & - & + & - & - \\
\hline Phenols & + & + & - & + & + \\
\hline Glycosides & + & - & - & + & - \\
\hline
\end{tabular}

- indicates absence; + indicates presence of corresponding phytochemical constituent.

$<100 \mathrm{mg} / \mathrm{kg} /$ day, the literature grades it as moderate, good, and very good, respectively $[27,39]$. Therefore, the seed of S. molle has a good antimalarial activity. However, the aqueous fraction is found to be inactive as its parasite suppression was less than $30 \%$ even at the highest dose administered. 


\section{Conclusion}

Acute toxicity test conducted on $S$. molle confirmed the safety of the plant up to a dose of $2000 \mathrm{mg} / \mathrm{kg}$. Furthermore, the findings of the present study indicate that the seed of Schinus molle has significant in vivo antimalarial activity. The highest antimalarial effect was exhibited by the $80 \%$ methanol crude extract at the highest dose tested. Among the fractions tested, the chloroform fraction was found to be the most active in suppressing the parasite indicating the possible localization of the active compounds in this fraction. Moreover, the data would provide evidence to uphold the earlier in vitro antimalarial investigation on the plant as well as the traditional use of the plant by the local communities for the treatment of malaria in Ethiopia. Consequently, the seed of Schinus molle could be used as a potential source to develop more effective and safer antimalarial drugs.

\section{Data Availability}

Vouchers and specimens of the experimental plant used for this study are deposited at the National Herbarium of Addis Ababa University, College of Natural Sciences. The datasets supporting the conclusion of this study are available from the corresponding author upon reasonable request.

\section{Ethical Approval}

The proposal was reviewed and approved by the Institutional Review Board of the Department of Pharmacology and Clinical Pharmacy, College of Health Sciences, Addis Ababa University.

\section{Conflicts of Interest}

The authors declare that they have no conflicts of interest.

\section{Authors' Contributions}

Getu Habte conceived the proposal and Teshome Nedi and Solomon Assefa reviewed it. Getu Habte performed the experiment and analyzed and interpreted the data. All authors participated in the write-up of the manuscript. All authors have read and approved the final manuscript.

\section{Acknowledgments}

The financial support of Addis Ababa University and Mettu University is gratefully acknowledged. The research was funded by the School of Graduate Studies of Addis Ababa University (research grant no. GSR/2597/09).

\section{References}

[1] F. E. G. Cox, "History of the discovery of the malaria parasites and their vectors," Parasites and Vectors, vol. 3, no. 1, p. 5, 2010.

[2] M. Mojarrab, A. Shiravand, A. Delazar, and F. Heshmati Afshar, "Evaluation of In vitro Antimalarial activity of different extracts of Artemisia aucheri Boiss. and A. armeniaca Lam. and fractions of the most potent extracts," The Scientific World Journal, vol. 2014, Article ID 825370, 6 pages, 2014.

[3] A. Alelign and T. Dejene, "Current status of malaria in Ethiopia: evaluation of the burden, factors for transmission and prevention methods," Acta Parasitologica Globalis, vol. 7, no. 1, pp. 1-6, 2016.

[4] S. Sabbatani, S. Fiorino, and R. Manfredi, "The emerging of the fifth malaria parasite (Plasmodium knowlesi): a public health concern?," The Brazilian Journal of Infectious Diseases, vol. 14, no. 3, pp. 299-309, 2010.

[5] A. M. Dondorp, "Pathophysiology, clinical presentation and treatment of cerebral malaria," Neurology Asia, vol. 10, pp. 67-77, 2005.

[6] Centers for Disease Control and Prevention, Malaria Burden, Center for Global Health, Division of Parasitic Diseases and Malaria, Atlanta, GA, USA, 2018.

[7] World Health Organization, World Malaria Report, World Health Organization, Geneva, Switzerland, 2017.

[8] World Health Organization, World Malaria Report, World Health Organization, Geneva, Switzerland, 2014.

[9] S. A. Fana, M. D. A Bunza, S. A. Anka, A. U. Imam, and S. U. Nataala, "Prevalence and risk factors associated with malaria infection among pregnant women in a semi-urban community of north-western Nigeria," Infectious Diseases of Poverty, vol. 4, no. 1, pp. 1-5, 2015.

[10] S. I. Hay, C. A. Guerra, A. J. Tatem, A. M. Noor, and R. W. Snow, "The global distribution and population at risk of malaria: past, present, and future," The Lancet Infectious Diseases, vol. 4, no. 6, pp. 327-336, 2004.

[11] D. Bhattacharjee and G. Shivaprakash, "Drug resistance in malaria-in a nutshell," Journal of Applied Pharmaceutical Science, vol. 6, no. 3, pp. 137-143, 2016.

[12] World Health Organization, Guidelines for the Treatment of Malaria, World Health Organization, Geneva, Switzerland, 3rd edition, 2015.

[13] V. Duru, B. Witkowski, and D. Ménard, "Plasmodium falciparum resistance to artemisinin derivatives and piperaquine: a major challenge for malaria elimination in Cambodia," The American Journal of Tropical Medicine and Hygiene, vol. 95, no. 6, pp. 1228-1238, 2016.

[14] Malaria Research, Centers for Disease Control and Prevention, Center for Global Health, Division of Parasitic Diseases and Malaria, Atlanta, GA, USA, 2017.

[15] H. Achenbach, R. Waibel, M. H. H. Nkunya, and H. Weenen, "Antimalarial compounds from Hoslundia opposita," Phytochemistry, vol. 31, no. 11, pp. 3781-3784, 1992.

[16] M. L. Willcox and G. Bodeker, "Traditional herbal medicines for malaria," BMJ, vol. 329, no. 7475, pp. 1156-1159, 2004.

[17] G. Alebie, B. Urga, and A. Worku, "Systematic review on traditional medicinal plants used for the treatment of malaria in Ethiopia: trends and perspectives," Malaria Journal, vol. 16, no. 1, pp. 1-13, 2017.

[18] M. Giday, T. Teklehaymanot, A. Animut, and Y. Mekonnen, "Medicinal plants of the shinasha, agew-awi and amhara peoples in northwest Ethiopia," Journal of Ethnopharmacology, vol. 110 , no. 3, pp. 516-525, 2007.

[19] O. Kenea and H. Tekie, "Ethnobotanical survey of plants traditionally used for malaria prevention and treatment in selected resettlement and indigenous villages in Sasiga District, Western Ethiopia," Journal of Biology, Agriculture and Healthcare, vol. 5, no. 11, pp. 1-9, 2015.

[20] E. Abdel-Sattar, L. Maes, and M. M. Salama, "In vitro activities of plant extracts from Saudi Arabia against malaria, 
leishmaniasis, sleeping sickness and Chagas disease," Phytotherapy Research, vol. 24, no. 9, pp. 1322-1328, 2010.

[21] National Academy of Sciences, Institute for Laboratory Animal Research, Division on Earth and Life Studies, National Academy of Sciences Guide for the Care and Use of Laboratory Animals, National Academy of Sciences, Institute for Laboratory Animal Research, Division on Earth and Life Studies, Washington, DC, USA, 8th edition, 2011.

[22] T. Yacob, W. Shibeshi, and T. Nedi, "Antidiarrheal activity of $80 \%$ methanol extract of the aerial part of Ajuga remota Benth (Lamiaceae) in mice," BMC Complementary Alternative Medicine, vol. 16, no. 1, p. 303, 2016.

[23] L. Bantie, S. Assefa, T. Teklehaimanot, and E. Engdawork, "In Vivo antimalarial activity of the crude leaf extract and solvent fractions of Croton macrostachyus Hocsht. (Euphorbiaceae) against $P$. berghei in mice," BMC Complementary and Alternative Medicine, vol. 14, no. 1, pp. 1-10, 2014.

[24] Organization of Economic Co-operation and Development (OECD), Guidelines for Testing of Chemicals: Guideline 425: Acute Oral Toxicity, Organization of Economic Co-operation and Development (OECD), Paris, France, 2008.

[25] T. Deressa, Y. Mekonnen, and A. Animut, "In vivo antimalarial activities of Clerodendrum myricoides, Dodonea angustifolia and Aloe debrana against P. berghei in mice," Ethiopian Journal of Health Development, vol. 24, no. 1, pp. 25-29, 2010.

[26] W. Peter, H. Portus, and L. Robinson, "The four day suppressive in vivo antimalarial test," Annals of Tropical Medicine and Parasitology, vol. 69, pp. 155-171, 1975.

[27] D. Nureye, S. Assefa, T. Nedi, and E. Engidawor, "In vivo antimalarial activity of $80 \%$ methanol root bark extract and solvent fractions of Gardenia ternifolia Schumach. \& Thonn. (Rubiaceae) against Plasmodium berghei infected mice," Evidence-Based Complementary and Alternative Medicine, vol. 2018, Article ID 9217835, 10 pages, 2018.

[28] S. Asnake, T. Teklehaymanot, A. Hymete, B. Erko, and M. Giday, "Evaluation of the antiplasmodial properties of selected plants in southern Ethiopia," BMC Complementary and Alternative Medicine, vol. 15, no. 1, pp. 1-12, 2015.

[29] O. C. U. Adumanya, A. A. Uwakwe, and E. B. Essien, "Antiplasmodial activity of methanol leaf extract of Salacia senegalensis Lam (Dc) in albino mice infected with chloroquine-sensitive Plasmodium berghei (NK65)," International Journal of Ethnopharmacology, vol. 1, no. 1, pp. 2-6, 2014.

[30] D. A. Fidock, P. J. Rosenthal, S. L. Croft, R. Brun, and S. Nwaka, "Antimalarial drug discovery: efficacy models for compound screening," Nature Reviews Drug Discovery, vol. 3, no. 6, pp. 509-520, 2004.

[31] B. Mengiste, E. Makonnen, and K. Urga, "In vivo antimalarial activity of Dodonaea angustifolia seed extracts against $P$. berghei in mice model," Momona Ethiopian Journal of Science, vol. 4, no. 1, pp. 47-63, 2012.

[32] D. Dikasso, E. Mekonnen, A. Debella et al., "Antimalarial activity of Withania somnifera L. Dunal extracts in mice," Ethiopian Medical Journal, vol. 44, no. 3, pp. 279-285, 2006.

[33] P. Tiwari, B. Kumar, M. Kaur, G. Kaur, and H. Kaur, "Phytochemical screening and extraction: a review," International Pharmaceutical Sciences, vol. 1, no. 1, pp. 98-106, 2011.

[34] S. C. Ugochukwu, I. A. Uche, and O. Ifeanyi, "Preliminary phytochemical screening of different solvent extracts of stem bark and roots of Dennetia tripetala G," Asian Journal of Plant Science and Research, vol. 3, no. 3, pp. 10-13, 2013.
[35] S. Fantahun, E. Maekonnen, T. Awas, and M. Giday, "In vivo antiplasmodium activity of crude extracts and solvent fractions of Strychnos mitis leaves in Plasmodium berghei infected mice," BMC Complementary and Alternative Medicine, vol. 17, no. 1, pp. 1-12, 2017.

[36] J. Okokon, A. D. Koofreh, and A. A. Bala, "Antipyretic and antimalarial activities of Solenostemon monostachyus," Pharmacological Biology, vol. 54, no. 4, pp. 648-653, 2016.

[37] K. Abi, H. Majdi, A. Manef, and A. Sameh, "Schinus molle: chemical analysis, phenolic compounds and evaluation of its antioxidant activity," Journal of Chemical and Pharmaceutical Research, vol. 8, no. 5, pp. 93-101, 2016.

[38] E. F. Silva-Júnior, P. G. V. Aquino, P. F. S. Santos-Júnior et al., "Phytochemical compounds and pharmacological properties from Schinus molle Linnaeus and Schinus terebinthifolius raddi (Anacardiaceae)," Journal of Chemical and Pharmaceutical Research, vol. 7, no. 12, pp. 389-393, 2015.

[39] V. Munoz, M. Sauvain, G. Bourdy et al., "A search for natural bioactive compounds in bolivia through a multidisciplinary approach. Part I. Evaluation of the antimalarial activity of plants used by the chacobo Indians," Journal of Ethnopharmacology, vol. 69, no. 2, pp. 127-137, 2000. 